\title{
SEBARAN TIMBAL DAN KADMIUM DALAM TERUMBU KARANG PERAIRAN KEPULAUAN SERIBU
}

\author{
June Mellawati ${ }^{1}$, dan Ramadian Bachtiar ${ }^{2}$ \\ (Diterima tanggal : 10-01-2011; Disetujui tanggal : 18-05-2011)
}

\begin{abstract}
The increasing of human activities in Jakarta and surrounding areas will contribute to environmental metal pollution at Kepulauan Seribu waters. As a group of small islands reefs, the Kepulauan seribu are potentially affected and is feared to disrupt the life of these reefs. The aim of research is to know how far the concentration of $\mathrm{Pb}$ and $\mathrm{Cd}$ can be recorded on the skeleton so that the coral reefs can provide a pollution description in the waters of the Kepulauan Seribu. This research used Porites stephensoni massive coral samples that obtained from waters around Bokor, Tikus, and Tidung Island of Kepulauan Seribu, North Jakarta. Analysis of $\mathrm{Pb}$ and $\mathrm{Cd}$ using atomic absorption spectrophotometer at wavelength 283 and $228 \mathrm{~nm}$, and the circumference of the year was done to determine the approximate age of the coral reefs, before. The results showed that the massive coral of Porites stephensoni each of which is expected to form in 1979, 1951, and 1972 is able to record a number of $\mathrm{Pb}$ and $\mathrm{Cd}$ metals. The ability of the massive coral Porites stephensoni record $\mathrm{Pb}$ and $\mathrm{Cd}$ showed that it have potential as a bioindicator of metal pollutants in the waters. Trend of the increasing $\mathrm{Pb}$ and $\mathrm{Cd}$ in the upper 2000s allegedly associated conditions Thousand Islands waters are getting worse, but have not seen the influence of $\mathrm{Pb}$ and $\mathrm{Cd}$ on the growth of coral Porites stephensoni significantly.
\end{abstract}

Keywords: Coral reef, $\mathrm{Pb}$ and $\mathrm{Cd}$ heavy metals, Seribu Island

\begin{abstract}
ABSTRAK
Meningkatnya berbagai kegiatan manusia di Jakarta dan sekitarnya akan memberikan kontribusi pencemaran logam ke lingkungan perairan Kepulauan Seribu. Sebagai sekelompok pulau karang-karang kecil, kepulauan Seribu sangat berpotensi terkena dampaknya dan dikhawatirkan dapat mengganggu kehidupan karang-karang tersebut. Tujuan penelitian untuk mengetahui sejauh mana konsentrasi $\mathrm{Pb}$ dan $\mathrm{Cd}$ dapat terekam pada skeleton terumbu karang sehingga terumbu karang dapat memberikan gambaran kondisi pencemaran di perairan Kepulauan Seribu. Pada penelitian ini digunakan sampel terumbu karang masif Porites stephensoni yang diperoleh dari perairan di sekitar Pulau Bokor, Pulau Tikus, dan Pulau Tidung Kepulauan Seribu, Jakarta Utara. Analisis Pb dan Cd menggunakan spektrofotometer serapan atom pada panjang gelombang 283 dan $228 \mathrm{~nm}$, dan sebelumnya dilakukan analisis lingkar tahun untuk mengetahui umur terumbu karang. Hasil penelitian menunjukkan bahwa terumbu karang masif Porites stephensoni yang masing-masing diperkirakan terbentuk tahun 1979, 1951, dan 1972 mampu merekam sejumlah logam $\mathrm{Pb}$ dan $\mathrm{Cd}$. Kemampuan terumbu karang masif Porites stephensoni merekam $\mathrm{Pb}$ dan $\mathrm{Cd}$ menunjukkan ada potensi sebagai bioindikator bahan pencemar logam di perairan. Kecenderungan peningkatan $\mathrm{Pb}$ dan $\mathrm{Cd}$ di atas tahun 2000an diduga terkait kondisi perairan kepulauan Seribu yang makin memburuk, namun belum terlihat pengaruh logam $\mathrm{Pb}$ dan $\mathrm{Cd}$ terhadap pertumbuhan terumbu karang Porites stephensoni secara signifikan.
\end{abstract}

Kata Kunci: Terumbu karang, logam berat $\mathrm{Pb}$ dan $\mathrm{Cd}$, Pulau Seribu

\section{PENDAHULUAN}

Struktur terumbu karang didominasi oleh endapan batu kapur bersifat masif mengandung kalsium karbonat $\left(\mathrm{CaCO}_{3}\right)$ hasil metabolisme biota laut (zooxanthellae) yang mensekresi kapur dan alga melalui proses kalsifikasi.
Salah satu jenis koral atau karang keras (hard coral) yaitu Porites sp yang berbentuk hampir membulat dan ukurannya cukup besar. Umumnya jenis karang Porites sp dipilih karena mempunyai kecepatan/laju

\footnotetext{
${ }^{1}$ Pusat Pengembangan Energi Nuklir- BATAN, Jl. Kuningan Barat, Mampang Jakarta Selatan. June_mellawati@yahoo.co.id

${ }^{2}$ Departemen Ilmu dan Teknologi Kelautan, Institut Pertanian Bogor
} 
pertumbuhan relatif besar, tahan terhadap kerusakan dan erosi, dan mampu merekam data lingkungan secara alami ${ }^{(1)}$. Pertumbuhan karang yang bersifat akresi atau lapis demi lapis tersebut secara terus menerus akan memungkinkan sejumlah logam yang terlarut dalam perairan terperangkap.

Kepulauan Seribu adalah sekelompok pulau karang kecil yang terletak sepanjang barat laut dari Teluk Jakarta, dan berjarak \pm $80 \mathrm{~km}$ dari kota Jakarta. Sejak beberapa dekade yang lalu, pulau-pulau ini mengalami tekanan terhadap lingkungannya akibat dampak kegiatan manusia. Pertumbuhan penduduk yang meningkat dan perkembangan pembangunan industri di Jakarta menyebabkan tekanan terhadap lingkungan hidup sekitar perairan Kepulauan Seribu semakin berat. Beberapa kegiatan tersebut diantaranya adalah pembuangan limbah industri, sampah rumah tangga dan penggunaan pupuk pertanian di daratan, serta penambangan minyak sangat berpotensi memberikan kontribusi logam ke lingkungan perairan yang cukup signifikan. Hasil penelitian sebelumnya dilaporkan kandungan $\mathrm{Cd}$ dan $\mathrm{Pb}$ dalam sampel air laut perairan Kepulauan Seribu masing-masing 0,0014-0,0040 ppm dan 0,0062-0,0074 ppm, dalam sedimen masing-masing 0,1536-3,0244 ppm dan 0,4260-1,5770 ppm, dalam biota kerang masing-masing 0,0067-0,0110 ppm dan 0,0043-0,0090 ppm, dan Cd dalam ikan bandeng $0,0080-0,0090 \mathrm{ppm}^{(2)}$.

Berdasarkan alasan tersebut dilakukan penentuan kandungan logam berat $\mathrm{Pb}$ dan $\mathrm{Cd}$ dalam terumbu karang dari perairan sekitar Kepulauan Seribu, khususnya Pulau Tidung, Bokor dan Tikus. Diharapkan data yang diperoleh dapat memberikan gambaran kemungkinan terumbu karang sebagai alat untuk mengetahui kondisi pencemaran perairan sekitar teluk Jakarta oleh berbagai kegiatan manusia.

Kawasan Pulau Bokor luasnya $18 \mathrm{Ha}$ dan secara geografis letaknya $\pm 3,5$ mil laut di sebelah barat Jakarta, yang secara administratif termasuk wilayah Kelurahan Pulau Lancang ${ }^{(3)}$. Pulau Tidung luasnya 100 Ha dan dikelilingi oleh pantai dangkal yang bergradasi putih karena ditumbuhi karang. Sebagai salah satu desa di Kepulauan Seribu bagian selatan terbagi dua yaitu Pulau Tidung Besar dan Pulau Tidung Kecil (4). Pulau Tikus dan Pulau Bokor termasuk Kelurahan Pulau Pari, Kecamatan Kepulauan Seribu Selatan, sedangkan Pulau Tidung termasuk Kelurahan Pulau Tidung, Kecamatan Kepulauan Seribu Selatan ${ }^{(5)}$.

\section{METODOLOGI}

\section{Lokasi Penelitian.}

Perairan Kepulauan Seribu, yaitu sekitar perairan Pulau Tidung $\left(05^{\circ} 48^{\prime} 22.0^{\prime}\right.$ ' LS, $106^{0}$ 31' 55.2” BT), Pulau Tikus (05 51' 52.8" LS, $106^{0} 35^{\prime} 07.5^{\prime \prime}$ BT) dan Pulau Bokor $\left(05^{\circ}\right.$ 56' 38.1” LS, $106^{0} 37$ '38.1” BT) (Gambar 1), merupakan tempat pengambilan sampel terumbu karang. 

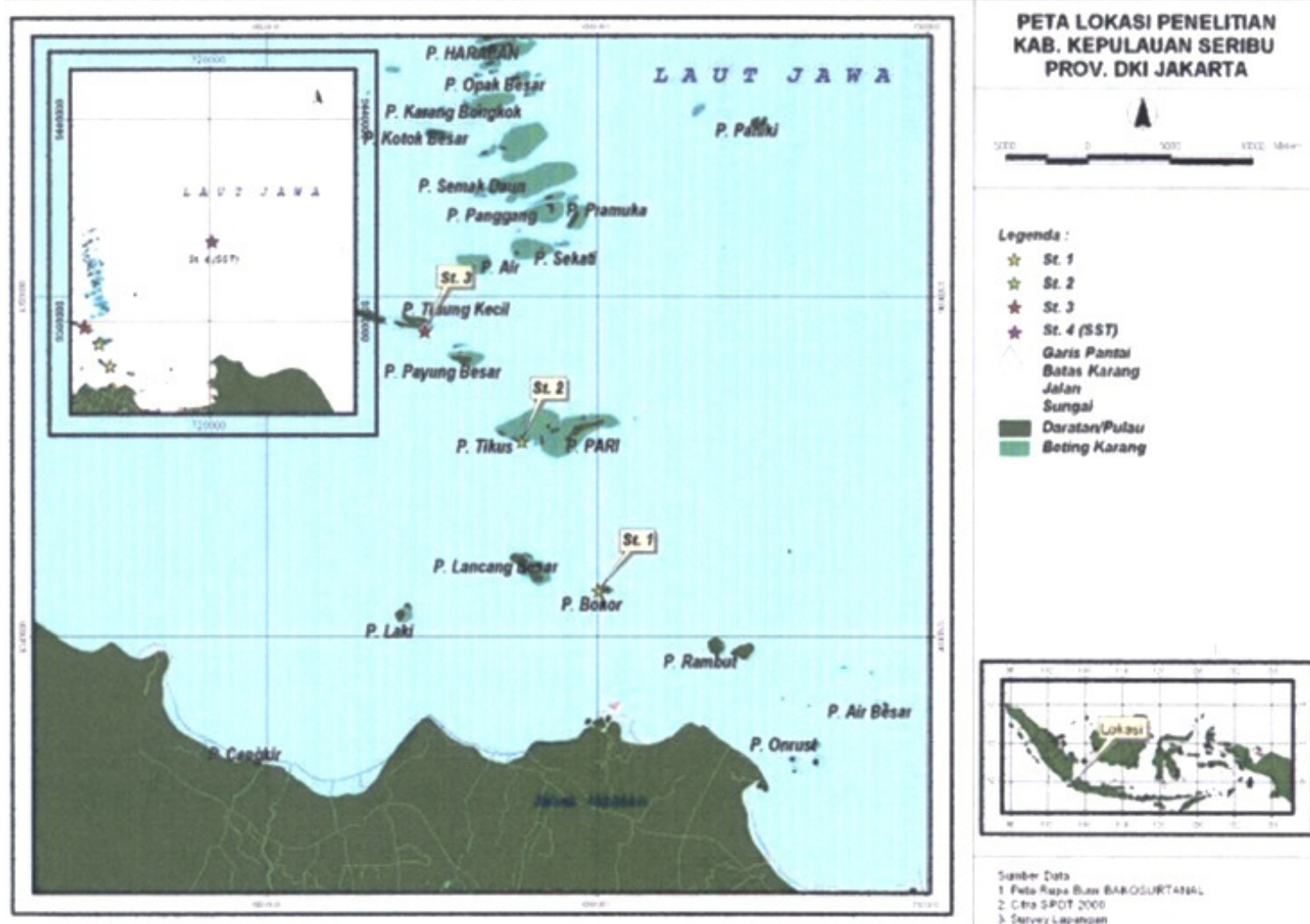

Gambar 1. Lokasi pengambilan sampel terumbu karang.

\section{Bahan dan Peralatan.}

Pada penelitian digunakan sampel karang jenis masif dari genus Porites sp. Bahan penelitian yaitu larutan $\mathrm{HNO}_{3}(65 \%), \mathrm{NaOH}(1 \mathrm{~N})$, serta larutan standar masing-masing mengandung $\mathrm{Pb}$ dan $\mathrm{Cd} 1000$ ppm.

Beberapa peralatan penelitian yaitu peralatan selam SCUBA (Self Contained Underwater Breathing Apparatus), gergaji belah, palu, kikir, pisau diamond, dan lampu flouresen. Peralatan untuk menentukan lingkar tahun adalah mesin $\mathrm{X}$-ray, sedangkan untuk menentukan logam $\mathrm{Pb}$ dan Cd adalah Spektrometer Serapan Atom.

\section{Pengambilan Sampel.}

Mula-mula dilakukan survei karang, dan dilanjutkan identifikasi karang secara in situ berdasarkan morfologi calice karang untuk mengetahui jenis karang masif yang dikehendaki. Sampel karang diperoleh secara acak di masing-masing pulau (stasiun) dan disampling pada kedalaman 2-5 meter dengan Scuba dan Snorkling. Sampel karang dipilih sebagai karang yang sudah cukup tua, berwarna agak gelap dan bentuknya hampir membulat. Pertumbuhan karang Porites sp ditunjukkan dari adanya pertumbuhan karang yang berselang seling dengan lapisan-lapisan gelap terang.

\section{Preparasi Sampel.}

Sampel karang spesies Porites stephensoni diperoleh dengan cara drilling menggunakan bor khusus, yaitu mata bor besi berbentuk tabung panjang $30 \mathrm{~cm}$. Alat bor digerakkan dengan bantuan tekanan udara dari tabung selam, secara tegak lurus atau miring dengan sudut kemiringan 45 derajat. Potongan sampel terumbu karang yang terkumpul 
diberi label, nomor dengan urutan dari atas ke bawah dan dibawa ke permukaan serta dimasukkan kedalam cooled box untuk dibawa ke laboratorium. Di laboratorium, sampel terumbu karang direndam dalam air tawar selama \pm 1 jam dan dikering anginkan. Selanjutnya dipotong secara vertikal dengan ketebalan $\pm 1 \mathrm{~cm}$ dengan pisau diamond, untuk keperluan analisis lingkar tahun.

\section{Analisis Lingkar Tahun Karang.}

Analisis lingkar tahun dilakukan dengan teknik Radiografi sinar-X, mula-mula potongan terumbu difoto dengan sinar-X dari MPCU $\mathrm{X}$-Ray berkekuatan $50 \mathrm{kVp}$ dengan periode 12 detik dan jarak fokus 1 meter. Hasil proses dalam bentuk film X-ray hitam putih direproduksi dengan kamera digital Nikon D70S untuk selanjutnya diolah dengan Adobe Photoshop CS2 dan Corel Draw. Hasil olahan foto dicetak dengan ukuran sebenarnya di atas plastik transparansi yang selanjutnya untuk pedoman lingkar tahun. Sebagian potongan terumbu karang dimasukkan ke dalam kantong plastik guna keperluan analisis kandungan logam $\mathrm{Pb}$ dan $\mathrm{Cd}$.

\section{Analisis Kandungan Pb dan $\mathrm{Cd}$.}

Potongan sampel karang dari setiap lapisan terumbu karang masing-masing dihaluskan hingga berbentuk serbuk dan dikeringkan dalam oven. Selanjutnya sampel serbuk ditimbang secara seksama, didestruksi menggunakan beberapa tetes larutan $\mathrm{HNO}_{3}$ (65\%) dan $\mathrm{H}_{2} \mathrm{O}_{2}(30 \%)$ hingga jernih, lalu disaring dan ditepatkan volumenya dengan air destilata. Pengukuran $\mathrm{Pb}$ dan $\mathrm{Cd}$ dilakukan menggunakan metode spektroskopi serapan atom pada panjang gelombang masing-masing 283 dan $228 \mathrm{~nm}$. Selain dilakukan preparasi sampel juga dilakukan preparasi deret standar $\mathrm{Pb}$ dan $\mathrm{Cd}$, serta blanko. Perhitungan konsentrasi menggunakan metode relatif dengan pembanding standar.

\section{HASIL DAN PEMBAHASAN}

\section{Hasil Analisis Lingkar Tahun.}

Hasil analisis terumbu karang dari Pulau Tidung menunjukkan bahwa ditemukan sebanyak 28 lapisan dengan tebal setiap lapisan berkisar antara 8-12 mm, sedangkan terumbu karang dari Pulau Tikus sebanyak 35 lapisan dengan tebal setiap lapisan berkisar antara 8-12 $\mathrm{mm}$, dan terumbu karang dari Pulau Bokor sebanyak 56 lapisan dengan tebal setiap lapisan berkisar antara 6-8 $\mathrm{mm}$ (Gambar 2).

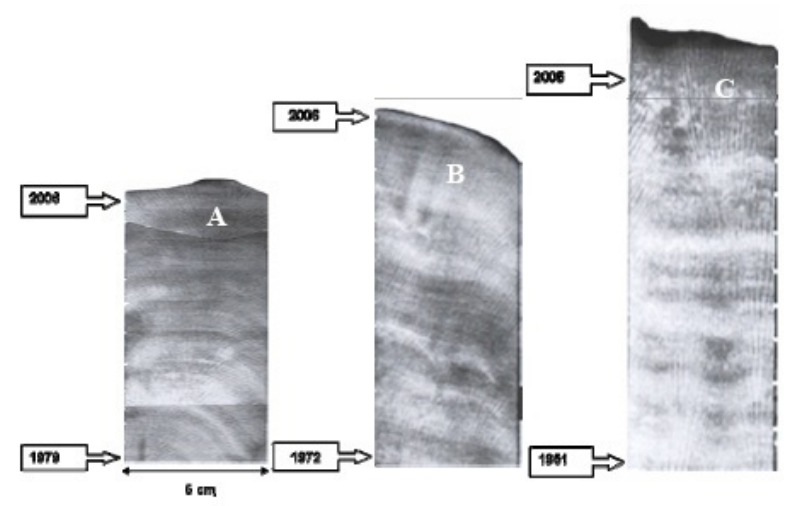

Gambar 2. Hasil pemotretan irisan terumbu karang dengan X-Ray, terumbu karang dari Pulau Tidung (A), Pulau Tikus (B) dan Pulau Bokor (C). 


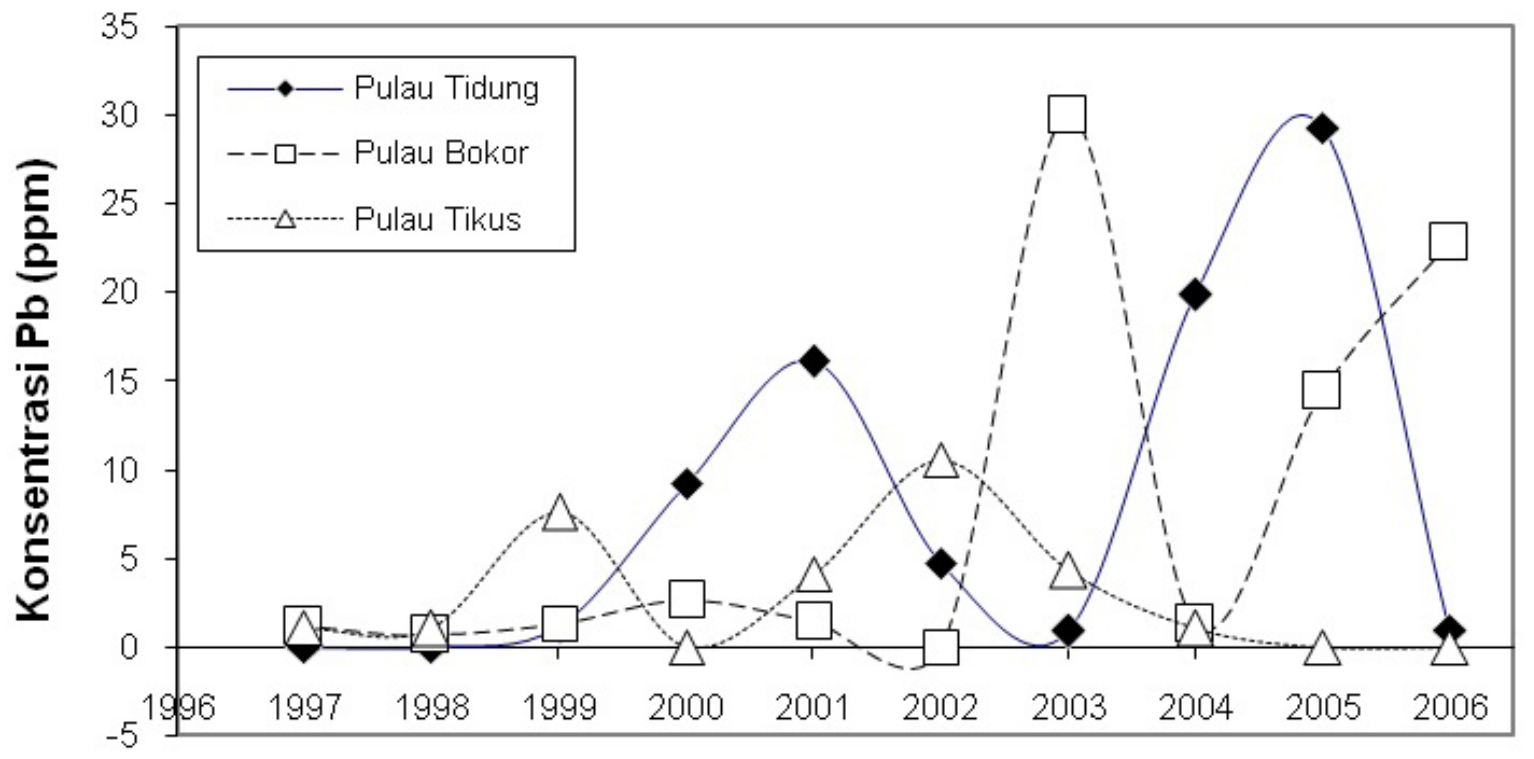

Tahun

Gambar 3. Pola sebaran logam $\mathrm{Pb}$ pada setiap lapisan/lingkar tahun terumbu karang spesies Porites stephensoni dari perairan sekitar Pulau Bokor, Tidung dan Tikus.

Terumbu karang dari Pulau Tidung (Gambar 2A) mempunyai pita lingkar tahun sebanyak 28 lapisan, sehingga diperkirakan terbentuk sejak tahun 1979. Laju pertumbuhan karang ditunjukkan lebar pita lingkar tahun yang berfluktuasi setiap tahunnya dan berkecenderungan lebih lebar di awal tahun pertumbuhan dibandingkan tahun-tahun menjelang 2006.

Terumbu karang dari Pulau Tikus (Gambar 2B) mempunyai pita lingkar tahun 35 lapisan, sehingga diperkira kan terbentuk sejak tahun 1972. Laju pertumbuhan karang di Pulau Tikus ini maih relatif baik seperti halnya di Pulau Tidung.

Terumbu karang dari Pulau Bokor (Gambar 2C) mempunyai pita lingkar tahun sebanyak 56 lapisan sehingga diperkirakan terbentuk sejak tahun 1951. Pulau Bokor adalah pulau terdekat dengan daratan Jakarta dibandingkan ke dua pulau lainnya (Pulau Tidung dan Tikus), laju pertumbuhan karang relatif lamban, hal ini diduga terkait dengan perairn sebagai media tumbuhnya yang banyak dipengaruhi oleh kegiatan daratan di Jakarta.

\section{Hasil Analisis Kandungan $\mathrm{Pb}$ dan $\mathrm{Cd}$}

Data sebaran logam $\mathrm{Pb}$ pada terumbu karang Porites stephensoni yang diperoleh dari perairan sekitar Pulau Bokor, Tidung dan Tikus Kepulauan Seribu ditunjukkan pada Gambar 3, sedangkan kadar rata-rata di setiap lingkar tahun ditunjukkan pada Tabel 1.

Tabel 1. Kadar rerata $\mathrm{Pb}$ pada terumbu karang

\begin{tabular}{|l|c|c|c|}
\hline $\begin{array}{c}\text { Lingkar } \\
\text { Tahun }\end{array}$ & $\begin{array}{c}\text { Pulau } \\
\text { Tidung }\end{array}$ & $\begin{array}{c}\text { Pulau } \\
\text { Tikus }\end{array}$ & $\begin{array}{c}\text { Pulau } \\
\text { Bokor }\end{array}$ \\
\hline 2006 & 0,98 & td & 22,76 \\
\hline 2005 & 29,27 & td & 14,39 \\
\hline 2004 & 19,88 & 1,02 & 1,32 \\
\hline 2003 & 0,88 & 4,30 & 29,94 \\
\hline 2002 & 4,75 & 10,56 & td \\
\hline 2001 & 1,07 & 4,15 & 1,42 \\
\hline 2000 & 9,25 & td & 2,64 \\
\hline 1999 & 16,14 & 7,63 & 1,35 \\
\hline 1998 & td & 1,03 & 0,65 \\
\hline 1997 & td & 1,11 & 1,19 \\
\hline
\end{tabular}

$\mathrm{td}=$ tidak terdeteksi 
Tabel 1 menunjukkan bahwa selama kurun waktu 10 tahun (1997-2006), terumbu karang Pulau Tidung, Pulau Tikus dan Pulau Bokor mampu merekam sejumlah $\mathrm{Pb}$. Konsentrasi tertinggi $\mathrm{Pb}$ pada terumbu karang dari Pulau Tikus ditemukan pada lingkar tahun 2004-2005 (19,88-29,28 ppm) (Gambar 3). Konsentrasi tertinggi $\mathrm{Pb}$ pada terumbu karang dari Pulau Tikus ditemukan pada lingkar tahun 2002 (10,56 ppm), sedang dari Pulau Bokor tertinggi ditemukan pada lingkar tahun 2003 (22,76 ppm) dan 2006 (29,95 ppm). Peneliti Yordania melaporkan, terumbu karang Porites sp. dari teluk Aqaba Yordania dan Venezuela yang umurnya 35 tahun (19601995) mampu merekam sejumlah $\mathrm{Pb}$, peneliti India melaporkan, terumbu karang dari Kepulauan Appa di perairan Teluk Mannar India mampu merekam $\mathrm{Pb}$ hingga 4,56 ppm, sedangkan terumbu karang dari Wadi ElGemal laut Merah Mesir mampu merekam $\mathrm{Pb}$ hingga 32 ppm (Porites lutea) dan 30,8 ppm (Porites compressa) $^{(6,7,8,9)}$.

Pola sebaran logam Cd pada terumbu karang Porites stephensoni dari perairan sekitar Pulau Bokor, Tidung dan Tikus Kepulauan Seribu ditunjukkan pada Gambar 4 dan data pada Tabel 2.

Tabel 2. Kadar rerata Cd pada terumbu karang

\begin{tabular}{|l|c|c|c|}
\hline $\begin{array}{c}\text { Lingkar } \\
\text { Tahun }\end{array}$ & $\begin{array}{c}\text { Pulau } \\
\text { Tidung }\end{array}$ & $\begin{array}{c}\text { Pulau } \\
\text { Tikus }\end{array}$ & $\begin{array}{c}\text { Pulau } \\
\text { Bokor }\end{array}$ \\
\hline 2006 & 1,72 & 0,10 & 4,78 \\
\hline 2005 & 0,83 & 1,14 & 1,43 \\
\hline 2004 & 1,83 & 0,48 & 0,24 \\
\hline 2003 & 1,31 & 0,22 & 1,14 \\
\hline 2002 & 1,80 & 0,98 & 0,23 \\
\hline 2001 & 2,24 & 2,29 & 0,34 \\
\hline 2000 & 1,08 & 3,64 & 0,57 \\
\hline 1999 & 1,38 & 1,69 & 1,20 \\
\hline 1998 & 0,45 & 0,86 & 1,16 \\
\hline 1997 & 1,56 & 1,32 & 1,73 \\
\hline
\end{tabular}

Tabel 2 menunjukkan bahwa selama kurun waktu 10 tahun (1997-2006) terumbu karang dari perairan sekitar Pulau Tidung, Pulau Tikus dan Pulau Bokor mampu merekam sejumlah $\mathrm{Cd}$. Konsentrasi $\mathrm{Cd}$ tertinggi pada terumbu karang dari Pulau Tikus pada lingkar tahun 2000 (3,64 ppm), dari Pulau Bokor pada lingkar tahun 2006 (4,78 ppm), dan dari Pulau Tidung pada lingkar tahun 2001 (2,24 ppm) (Gambar 4). Peneliti India melaporkan, terumbu karang dari Kepulauan Appa di perairan Teluk Mannar di India mampu merekam Cd hingga

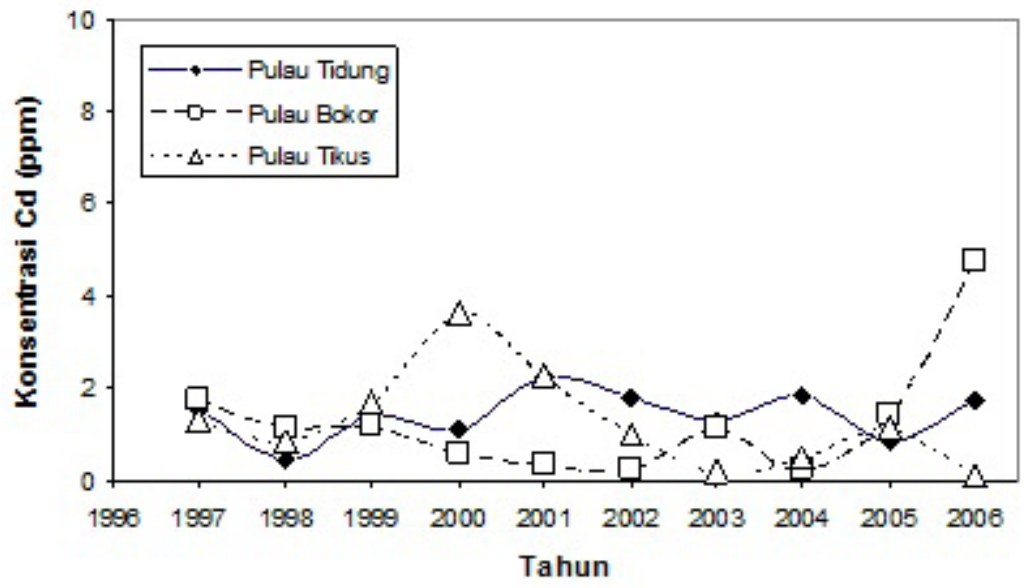

Gambar 4. Pola sebaran logam Cd pada setiap lapisan/lingkar tahun terumbu karang spesies Porites stephensoni dari perairan sekitar Pulau Bokor, Tidung dan Tikus . 
1,31 ppm, terumbu karang dari Wadi El-Gemal perairan laut Merah Mesir (Porites lutea dan Porites compressa) mampu merekam $\mathrm{Cd}$ masing-masing 0,2 ppm $^{(8,9)}$. Secara umum kandungan logam $\mathrm{Cd}$ dalam terumbu karang massif Porites stephensoni relatif lebih rendah dibandingkan logam $\mathrm{Pb}$.

Dibandingkan hasil penelitian dari India maupun Mesir, terumbu karang dari perairan Kepulauan Seribu Jakarta Indonesia juga mempunyai kemampuan merekam sejumlah $\mathrm{Pb}$ maupun $\mathrm{Cd}$ walaupun konsentrasinya sedikit berbeda. Hasil penelitian $\mathrm{Pb}$ dan $\mathrm{Cd}$ dalam terumbu karang menunjukkan relatif lebih tinggi bila dibandingkan $\mathrm{Pb}$ dan $\mathrm{Cd}$ dalam air dan sedimen perairan Kepulauan Seribu yang dilaporkan sebelumnya. Hal ini menunjukkan bahwa terumbu karang masif Porites stephensoni dimungkinkan sebagai perekam cemaran logam di suatu perairan.

Seperti diketahui, $\mathrm{Cd}$ dan $\mathrm{Pb}$ banyak ditemukan pada mineral-mineral sulfida. Dalam kegiatan industri, $\mathrm{Cd}$ banyak digunakan dalam industri electroplating, baterai, cat pigmen, stabilisator untuk PVC dan bahan paduan, sedangkan $\mathrm{Pb}$ dalam industri baterai, mobil, bahan pewarna keramik dan cat. Logam $\mathrm{Cd}$ juga terdapat sebagai unsur pengotor pupuk fosfat, deterjen dan produk minyak olahan ${ }^{(10)}$.

Keberadaan logam $\mathrm{Pb}$ dan $\mathrm{Cd}$ di perairan Jakarta Utara diduga terkait dengan pemanfaatan bahan yang mengandung logamlogam tersebut oleh berbagai industri di Utara Jakarta yang umumnya kurang tertib dalam pengolahan limbahnya.

\section{KESIMPULAN}

Berdasarkan hasil penelitian dapat disimpulkan bahwa:

- Skeleton terumbu karang jenis masif mampu merekam sejumlah logam $\mathrm{Pb}$ dan Cd selama kurun waktu lebih dari sepuluh tahun dengan konsentrasi relatif bervariasi.

- Kecenderungan terjadinya peningkat -an kandungan $\mathrm{Pb}$ dan $\mathrm{Cd}$ di terumbu karang pada tahun-tahun di atas tahun 2000 diduga terkait adanya perubahan kondisi perairan di Kepulauan Seribu yang lebih tercemar dibandingkan tahun-tahun sebelumnya.

- Dimungkinkannya terumbu karang masif Porites stephensoni sebagai perekam cemaran logam, maka ada potensi sebagai bioindikator bahan pencemar.

- Sejauh ini, belum terlihat secara signifikan adanya pengaruh logam $\mathrm{Pb}$ dan $\mathrm{Cd}$ terhadap pertumbuhan terumbu karang Porites sp.

\section{DAFTAR PUSTAKA}

1. Thierry Correge. 2006. "Monitoring of Terrestrial Input By Massive Corals". Journal of Geochemical Exploration, 88: 380-383.

2. Harry Sudradjat Johari, 2009, "Analisis Pencemaran Logam Berat $\mathrm{Cu}, \mathrm{Cd}$ Dan Pb Di Perairan Kabupaten Administrasi Kepulau an Seribu Provinsi Daerah Khusus Ibukota Jakarta, Studi kasus Pulau Panggang 
dan Pramuka", Tesis pada Program Studi Pengelolaan Sumberdaya Alam dan Lingkung an, Sekolah Pasca Sarjana, IPB Bogor.

3. BKSDA, 2009. "Cagar Alam Pulau Bokor",. (http://bksdadki jakarta. com/?page_id=22. July - $10-2009$. Diakses Juli 2010).

4. Wikipedia. 2009. "Pulau Tidung, Kepulauan Seribu Selatan, Kepulauan Seribu". (http://id.wiki pedia.org/ wiki/Pulau_Tidung,_Kepulauan_ Seribu_Selatan,_Kepulauan_Seribu. Diakses Juli 2010).

5. Peraturan Daerah Propinsi Daerah Khusus Ibukota Jakarta, No. 4 Tahun 2001 tentang Pembentuk kan Kecamatan Kepulauan Seribu Utara Dan Kecamatan Kepulauan Seribu Selatan Kabupaten Administrasi Kepulauan Seribu, Jakarta.

6. Saber A. Al-Rousan, Rashid N. AlShloul, Fuad A. Al-Horani, Ahmad H. Abu-Hilal. 2007. "Heavy metal contents in growth bands of Porites corals: Record of anthropogenic and human developments from the Jordanian Gulf of Aqaba",
Marine Pollution Bulletin Volume 54(12):1912-1922

7. C. Bastidas, E. García. 1999. "Metal Content on the Reef Coral Porites astreoides: an Evaluation of River Influence and 35 Years of Chronology". Marine Pollution Bulletin. Volume 38: 10, 899-907.

8. S. Krishna Kumar, N. Chandrasekar, P. Seralathan.2010. “Trace Elements Contamination in Coral Reef Skeleton, Gulf of Mannar India”. Bulletin Environ -mental Contamination Toxicology 8: 141-146.

9. Hashem Abbas Madkour. 2005. "Geochemical And Environmental Studies Of Recent Marine Sediments And Some Hard Corals Of Wadi ElGemal Area of The Red Sea, Egypt", Egyptian Journal of Aquatic Research Volume 31(1): 69-91

10. Sofia Banu Shah. 2008. Study of Heavy Metal accumulation in scleractinian Corals of Viti Levu, Fiji Islands. Master Thesis School of Marine Sciences Faculty of Islands and Oceans University of the South Pacific Suva, Fiji Islands, February 2008. 